\title{
STUDY THE ROLE OF VITAMIN D IN THE PATHOPHYSIOLOGY OF SEVERE ASTHMA
}

\author{
Maha Ibrahim ${ }^{(1)}$, Mohamed El-Ghazali ${ }^{(1)}$, Seham Abou-Shousha ${ }^{(2)}$, Mamdouh El-Yamany ${ }^{(1)}$ and \\ Nouran Abdel Raouf ${ }^{(1)}$ \\ ${ }^{(1)}$ Department of Human Physiology, ${ }^{(2)}$ Department of Immunology, Medical Research Institute, \\ Alexandra University, Egypt.
}

\section{ABSTRACT:}

Background: Vitamin D deficiency has been suggested to play a role in the pathophysiology of asthma. Several suggested mechanisms have been proposed including airway remodelling. The aim of our study was to investigate the role of vitamin D serum level in the pathophysiology of airway remodelling in severe refractory asthma.

Subjects and methods: The present study was conducted on 20 severe, 10 non-severe asthma patients and 15 control subjects. Pulmonary function tests, sputum matrix metalloproteinase-9 (MMP-9) and serum vitamin $\mathrm{D}_{3}$ were measured in all subjects. Patients with airway obstruction (Forced expiratory volume in one second $\left.\left(\mathrm{FEV}_{1}\right)<80 \%\right)$ performed bronchodilator reversibility testing.

Results:Vitamin D deficiency was prevalent among all our asthma patients. Although there was no significant difference in serum vitamin D levels between severe and non-severe asthmatic patients, serum vitamin D levels were positively correlated with the degree of current clinical control, as measured by Asthma Control Test (ACT). Serum vitamin D levels were negatively correlated with sputum MMP-9 levels in our asthma patients. The degree of bronchodilator reversibility was positively correlated with serum vitamin D and negatively correlated with sputum MMP-9 levels. Accordingly, we suggest that vitamin D may have a beneficial role in the prevention of airway remodelling in asthma patients.

Key Words: Asthma - airway remodelling - matrix metalloproteinase - severe asthma vitamin $D$.

\section{INTRODUCTION}

Asthma is a heterogeneous disease, usually characterized by chronic airway inflammation. It is defined by the history of respiratory symptoms such as wheeze, shortness of breath, chest tightness and cough that vary over time and in intensity, together with variable expiratory airflow limitation. ${ }^{(1)}$

Asthma is one of the most common chronic diseases worldwide, representing a major public health problem. Most patients have mild-to moderate asthma that can be relatively well controlled by the use of currently available medications ${ }^{(2)}$. However, $5-10 \%$ of patients suffer from a particularly severe disease that is poorly controlled clinically and often refractory to usual treatment. Improved care of patients with severe asthma is a major medical problem and several international research groups aim to improve our understanding of mechanisms in severe asthma. ${ }^{(2,3)}$

It has become clear that severe asthma represents a disease entity that differs from mild and moderate asthma in pathology and disease mechanisms. Airway remodelling, particularly increased airway smooth muscle (ASM) mass and subepithelial fibrosis has been specifically associated with severe asthma. It is assumed to result in persistent airflow limitation, decreased in lung function, and increased airway hyper-responsiveness (AHR). ${ }^{(4)}$

Matrix metalloproteinases (MMPs) are the key enzymes responsible for extracellular matrix (ECM) degradation. MMP-9 is one of the most relevant of the MMPs currently identified in asthma. ${ }^{(5)}$ It plays a role in airway remodelling as it has been associated with increased deposition of ECM proteins ${ }^{(6)}$ and ASM mass. ${ }^{(7)}$ In addition, MMP-9 has been suggested to enhance inflammatory cells trafficking through tissue to the site of injury through ECM degradation. ${ }^{(8)}$

Vitamin D deficiency is now considered as a public health problem affecting a wide range of acute and chronic diseases (9). Vitamin D deficiency has been suggested to play a role in the pathophysiology of asthma in general and severe asthma in particular. Some studies suggested a link between vitamin $\mathrm{D}$ deficiency and asthma morbidity in children and adults. $(10,11)$ Suggested mechanisms have been proposed including airway remodelling. ${ }^{(11,12)}$

An in vitro study demonstrated that $1,25-(\mathrm{OH})_{2} \mathrm{D}_{3}$ caused direct inhibitory effects on passively sensitized human ASMs, including inhibition of cell 
proliferation and expression of MMP-9. (11) This may suggest a hypothesis that lower vitamin D levels could lead to an increase in ASM mass, with subsequent MMP-9 release and ECM degradation, and thus airway remodeling. However, the clinical relevance of this study in subjects with severe refractory asthma is yet to be determined. The aim of our present work was to investigate the role of vitamin $\mathrm{D}$ serum level in the pathophysiology of airway remodelling in severe refractory asthma.

\section{SUBJECTS}

Thirty patients with asthma were recruited from those attending the Clinical Physiology unit at Medical Research Institute, Alexandria University, from November 2012 until February 2013. They were divided into 2 groups: 20 patients with severe refractory asthma as defined by the American Thoracic Society (ATS) ${ }^{(13)}$ and 10 patients with Non-severe asthma (i.e. not fulfilling the criteria of severe refractory asthma), taken as a reference group.

Fifteen control subjects, of matched age, weight, height and gender, were included in this study; none of them or of their first-degree relatives had suffered from asthma or other atopic disorders. The patients and the control subjects were non-smokers. None of them had symptoms of respiratory infection within four weeks before the beginning of the study. Subjects with history of other respiratory diseases, diabetes mellitus, cardiovascular, renal, hepatic or endocrinal diseases were excluded.

Full medical history and routine physical examination were performed to all patients. Asthma control was determined by asthma control test (ACT) ${ }^{(14)}$ and the frequency of severe exacerbation(s) (i.e. requiring systemic corticosteroids) in the previous year. Patients withheld short acting beta-2 agonists (SABA) for 4 hours and other asthma medications including long acting beta2 agonists (LABA), for 12 hours before examination This study was approved by Medical Research Institute ethics committee (IORG0008812). A written consent was obtained from every participant before being involved in the study.

\section{Pulmonary function tests:}

Pulmonary function tests were performed as adopted by American Thoracic Society/European Respiratory Society (ATS/ERS) Task Force ${ }^{(15,16)}$ and employed using computerized spirometer (Erich Jaeger GmbH D-97204). All subjects performed baseline pulmonary function tests. Patients with airway obstruction (Forced expiratory volume in 1 second $\left(\mathrm{FEV}_{1}<80 \%\right)$ ) performed bronchodilator reversibility testing. Three patients with severe asthma were not able to perform good quality bronchodilator reversibility testing due to excessive coughing.

\section{Measurement of serum vitamin D:}

Blood samples were collected during the examination. Serum levels of 25-hydroxyvitamin $\mathrm{D}_{3}$ (hereafter referred to as vitamin D) were measured using Shimadzu High Performance Liquid Chromatography (HPLC) technique. ${ }^{(17)}$ Serum level of 25-hydroxyvitamin $\mathrm{D}_{3}$ is considered the best circulating biomarker of vitamin D metabolic status because it reflects the contributions from all sources of vitamin D (i.e.,dietary intake and sunlight exposure). ${ }^{(18,19)}$
We categorized vitamin $\mathrm{D}$ levels as sufficient $(\geq 20$ $\mathrm{ng} / \mathrm{mL})$ or deficient $(<20 \mathrm{ng} / \mathrm{mL})$ based on previous recommendations ${ }^{(19)}$.

\section{Measurement of sputum MMP-9:}

Sputum induction $(20,21)$ and processing (22) were performed according to standardized procedures. Sputum supernatants were frozen and stored at $-80^{\circ} \mathrm{C}$ until analyzed for determination of MMP-9 level in the sputum of all studied groups. ${ }^{(23)}$ Sputum MMP-9 was then measured by Enzyme Linked Immunosorbant Assay (ELISA) kit (Human MMP-9 Platinum ELISA, eBioscience).

\section{STATISTICAL METHODS}

Data were analyzed using the Statistical Package for Social Sciences (SPSS, version 20, Chicago, IL, USA). The distributions of quantitative variables were tested for normality using Kolmogrov-Smirnov test. Differences between three groups were assessed using ANOVA (for normally distributed data) or Kruskal-Wallis test (for nonnormally distributed data). Differences between two groups were assessed using Student t-test (for normally distributed data) or Mann Whitney (non-normally distributed data). Association between gender of asthma and qualitative variables was assessed by Monte Carlo test. Correlations between quantitative variables were assessed using the Pearson correlation (for normally distributed data) or the Spearman's rank correlation (for non-normally distributed data). In all statistical tests, level of significance of $\mathrm{p}<0.05$ was used, below which the results were considered to be statistically significant.

\section{RESULTS}

\section{Subjects:}

Table (1) presents the demographic data of the studied subjects (non-asthma controls, non-severe and severe asthma). There were no significant differences between controls and asthma patients in gender, age and BMI. As regards asthma control, severe asthma patients had a significantly lower ACT scores and more frequent severe asthma exacerbations (i.e. requiring systemic corticosteroids) than patients with non-severe asthma (Table 1).

\section{Pulmonary function tests:}

\section{a)Baseline pulmonary function tests:}

Patients with severe asthma had significantly lower vital capacity (VC) and inspiratory capacity (IC), when compared to non-severe asthma patients and controls. There were no significant differences in these values between non-severe asthma patients and controls. In addition, there were no significant differences in expiratory reserve volume (ERV) between the three groups (Figure 1 (a)). and $\mathrm{FEV}_{1} / \mathrm{FVC}$ compared to nonsevere asthma patients and controls (Figure1(b). In asthma patients with airway obstruction (baseline $\mathrm{FEV}_{1}<$ $80 \%)(\mathrm{n}=18), \mathrm{VC}$, and IC significantly increased after bronchodilation; however, there was no significant difference between baseline and postbronchodilator ERV. As regards flow rates, FVC, $\mathrm{FEV}_{1}$, and PEF significantly improved after bronchodilation. However, there were no 
significant differences between baseline and postbronchodilator values in $\mathrm{FEV}_{1} / \mathrm{FVC}$ (Table 2).

\section{Vitamin D status (serum vitamin D):}

Serum vitamin D levels (ng/ml, Mean \pm SD) were significantly higher in controls $(28.50 \pm 16.87)$ than nonsevere $(7.43 \pm 3.41)$ and severe asthma patients $(5.96 \pm$ 3.70) $(\mathrm{p}<0.001)$. However, there was no significant difference in serum vitamin D levels between non-severe and severe asthma patients. All our asthma patients whether severe or non-severe had vitamin D deficiency compared to $33.3 \%$ of controls (Table 1, Figure 2)

\section{Serum vitamin D levels and asthma control:}

Serum vitamin D levels were significantly correlated with ACT in asthma patients $(r=0.498, p=0.005)$ (Figure 3 ). However, there was no significant correlation between serum vitamin D levels and the frequency of severe asthma exacerbation in the previous year.

Serum vitamin $D$ and pulmonary function tests in asthma patients:

Serum vitamin D levels were positively associated with baseline ERV $\left(r_{s}=0.368, p=0.045\right)$ (Figure 4). Otherwise, there was no significant association between serum vitamin D levels and any parameter in pulmonary function tests whether baseline or after bronchodilatation. As regards the bronchodilator response, higher serum vitamin $\mathrm{D}$ levels were associated with more improvement in IC ( $r=0.473, p=0.048)$ (Figure 5).

\section{Sputum MMP-9 levels:}

Sputum MMP-9 levels (ng/ml, Median (Min - Max)) in control, non-severe and severe asthma patients were 51.46
(7.16 - 270.0), $114.26(7.50-422.0)$ and $19.42(2.55-$ $358.0)$ respectively. There were no significant differences in sputum MMP-9 concentrations in the three studied groups (Table 1), (Figure 6).

\section{Sputum MMP-9 and asthma control:}

There was no significant correlation between sputum MMP-9 levels and ACT scores in asthma patients $\left(r_{s}=0.030, p=0.876\right)$. However, there was a significant negative association between sputum MMP-9 levels and the frequency of severe asthma exacerbation in the previous year $\left(\mathrm{r}_{\mathrm{s}}=-0.396, \mathrm{p}=0.030\right)$ (Figure 7$)$.

\section{Sputum MMP-9 and pulmonary function tests in asthma patients:}

Sputum MMP-9 levels were positively associated with baseline $\mathrm{FEV}_{1} / \mathrm{FVC} \%(\mathrm{r}=0.504, \mathrm{p}=0.005)$ (Figure 8), PEF $(\mathrm{r}=0.447, \mathrm{p}=0.013)$ and $\mathrm{FEF}_{25 \%}(\mathrm{r}=0.413, \mathrm{p}=0.023)$. After brochodilatation, sputum MMP-9 was inversely correlated with FVC $(r=-0.525, p=0.025)$. Otherwise, there were no significant associations between sputum MMP-9 levels and any other parameter in pulmonary function tests whether baseline or after bronchodilatation. Higher sputum MMP-9 levels were associated with lower degrees of improvement in $\mathrm{FEV}_{1}$ ( $\mathrm{r}=-0.483, \mathrm{p}=0.023$ ) (Figure 9). However, there were no significant associations between sputum MMP-9 level and any change in other parameters.

Correlation between serum vitamin $D$ and sputum MMP-9 levels in asthma patients:

Serum vitamin D levels were significantly inversely correlated with sputum MMP-9 levels in our asthmatic patients $\left(\mathrm{r}_{\mathrm{s}}=-0.377, \mathrm{p}=0.040\right)$ (Figure 10).

Table (1): Characteristics of the three studied groups

\begin{tabular}{|c|c|c|c|c|}
\hline & $\begin{array}{c}\text { Control(GI) } \\
(\mathrm{n}=15)\end{array}$ & $\begin{array}{c}\text { Non-severe asthma (GII) } \\
(\mathrm{n}=\mathbf{1 0})\end{array}$ & $\begin{array}{c}\text { Severe asthma(GIII) } \\
(\mathrm{n}=\mathbf{2 0})\end{array}$ & p \\
\hline Female gender, no. $(\%)$ & $12(80 \%)$ & $9(90 \%)$ & $17(85 \%)$ & $0.882^{\mathrm{a}}$ \\
\hline \multicolumn{5}{|l|}{ Age, years } \\
\hline Mean \pm SD & $37.0 \pm 10.41$ & $39.20 \pm 11.71$ & $43.05 \pm 10.45$ & \multirow[t]{2}{*}{$0.253^{\mathrm{b}}$} \\
\hline Range & $26.0-60.0$ & $17.0-57.0$ & $26.0-60.0$ & \\
\hline \multicolumn{5}{|l|}{ BMI, $\mathrm{Kg} / \mathrm{m}^{2}$} \\
\hline Mean \pm SD & $30.39 \pm 5.03$ & $34.30 \pm 4.87$ & $34.58 \pm 8.06$ & \multirow[t]{2}{*}{$0.154 \mathrm{~b}$} \\
\hline Range & $22.15-38.21$ & $26.20-42.97$ & $20.50-50.70$ & \\
\hline \multicolumn{5}{|l|}{ Vitamin D category, no. $(\%)$} \\
\hline$<20 \mathrm{ng} / \mathrm{ml}$ & $5(33.3 \%)$ & $10(100 \%)$ & $20(100 \%)$ & \multirow{2}{*}{$<0.001^{\mathrm{a}}$} \\
\hline$\geq 20 \mathrm{ng} / \mathrm{ml}$ & $15(66.7 \%)$ & - & - & \\
\hline \multicolumn{5}{|l|}{ Vitamin D level, ng/ml } \\
\hline Mean \pm SD & $28.50 \pm 16.87$ & $7.43 \pm 3.41$ & $5.96 \pm 3.70$ & \multirow[t]{2}{*}{$<0.001^{\mathrm{b}}$} \\
\hline Range & $(3.60-60.0)$ & $(2.90-12.80)^{\text {** }}$ & $(0.80-14.0)^{* * *}$ & \\
\hline \multicolumn{5}{|l|}{ Sputum MMP-9level, ng/ml } \\
\hline Mean \pm SD & $88.49 \pm 88.91$ & $139.56 \pm 137.71$ & $88.77 \pm 122.16$ & \multirow{3}{*}{$0.312^{\mathrm{c}}$} \\
\hline Median & 51.46 & 114.26 & 19.42 & \\
\hline Range & $(7.16-270.0)$ & $(7.50-422.0)$ & $(2.55-358.0)$ & \\
\hline$\overline{\mathrm{ACT}}$ & - & & & \\
\hline Mean \pm SD & & $15.4 \pm 3.75$ & $12.20 \pm 4.02$ & $2.100^{\mathrm{d}}$ \\
\hline Range & & $(12.0-21.0)$ & $(6.0-19.0)^{\#}$ & \\
\hline \multirow{3}{*}{$\begin{array}{l}\text { Frequency of severe exacerbations } \\
\text { per year } \\
\text { Mean } \pm \text { SD } \\
\text { Range }\end{array}$} & - & \multirow{3}{*}{$\begin{array}{c}0.50 \pm 0.972 \\
\quad(0-3.0)\end{array}$} & & \multirow{3}{*}{$3.669^{\mathrm{e}}$} \\
\hline & & & $5.05 \pm 4.286$ & \\
\hline & & & $(0-12)^{@}$ & \\
\hline
\end{tabular}

ACT: Asthma Control Test, BMI: Body mass index, MMP-9: Matrix metalloproteinase-9.

a: $p$ value calculated by Monte Carlo test, b: $p$ value calculated by F test (ANOVA), c: p value calculated by Kruskal Wallis test, d: $p$ value calculated by Student t-test, e: p value calculated by Mann Whitney test

$* *$ : Comparison between controls and non-severe asthmatics statistically significant at $\mathrm{p} \leq 0.01$

$* * *$ : Comparison between controls and severe asthmatics statistically significant at $\mathrm{p} \leq 0.001$

\#: Comparison between non-severe and severe asthmatics statistically significant at $\mathrm{p}<0.05$

@ : Comparison between non-severe and severe asthmatics statistically significant at $\mathrm{p}<0.001$ 
Table (2): Comparison between baseline and postbronchodilator pulmonary functions (Mean \pm SD) in asthmatic patients with airway obstruction $(\mathrm{n}=18)$

\begin{tabular}{lcccc}
\hline & Baseline & Post-bronchodilator & t & p \\
\hline VC & $68.03 \pm 16.93$ & $79.81 \pm 17.09$ & $4.619^{*}$ & $<0.001$ \\
IC & $73.45 \pm 25.09$ & $84.23 \pm 23.16$ & $3.784^{*}$ & 0.001 \\
ERV & $72.69 \pm 31.02$ & $78.64 \pm 32.52$ & 1.430 & 0.368 \\
FVC & $68.97 \pm 13.84$ & $79.83 \pm 12.93$ & $6.391^{*}$ & $<0.001$ \\
FEV $_{1}$ & $56.99 \pm 15.04$ & $68.23 \pm 18.07$ & $5.577^{*}$ & $<0.001$ \\
FEV $\mathbf{1}$ /FVC & $70.58 \pm 14.64$ & $72.52 \pm 15.64$ & 0.640 & 0.530 \\
PEF & $46.44 \pm 17.27$ & $55.74 \pm 17.83$ & $3.650^{*}$ & 0.002 \\
\hline
\end{tabular}

VC: vital capacity, IC: inspiratory capacity, ERV: expiratory reserve volume, FVC: forced vital capacity, FEV1: forced expiratory volume in 1 second, and PEF: peak expiratory flow

Data are presented as percent predicted values except for FEV1/FVC is presented as a ratio.

t: Paired t-test. *: Statistically significant at $\mathrm{p} \leq 0.05$
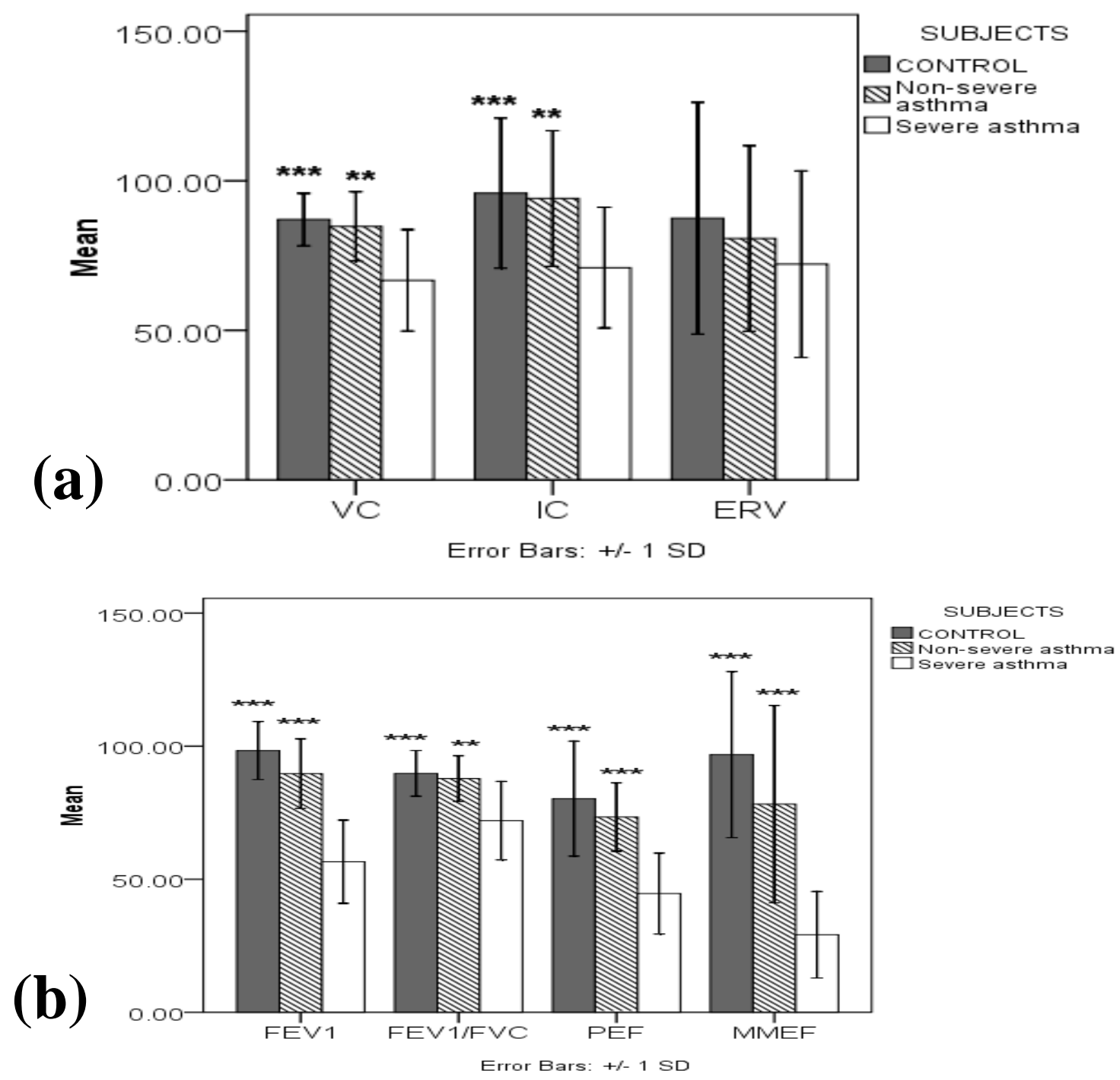

Figure 1 (a) and (b): Comparison between baseline (a) VC, IC and ERV (b) $\mathrm{FEV}_{1}, \mathrm{FEV}_{1} / \mathrm{FVC} \%$, PEF and MMEF in the three studied groups (control, non-severe and severe asthma patients).

VC: vital capacity, IC: inspiratory capacity, ERV: expiratory reserve volume, FEV1: forced expiratory volume in 1 second, FVC: forced vital capacity, PEF: peak expiratory flow and MMEF: maximum mid expiratory flow.

**: Comparison with severe asthmatics statistically significant at $\mathrm{p} \leq 0.01$,

***: Comparison with severe asthmatics statistically significant at $\mathrm{p} \leq 0.001$ 


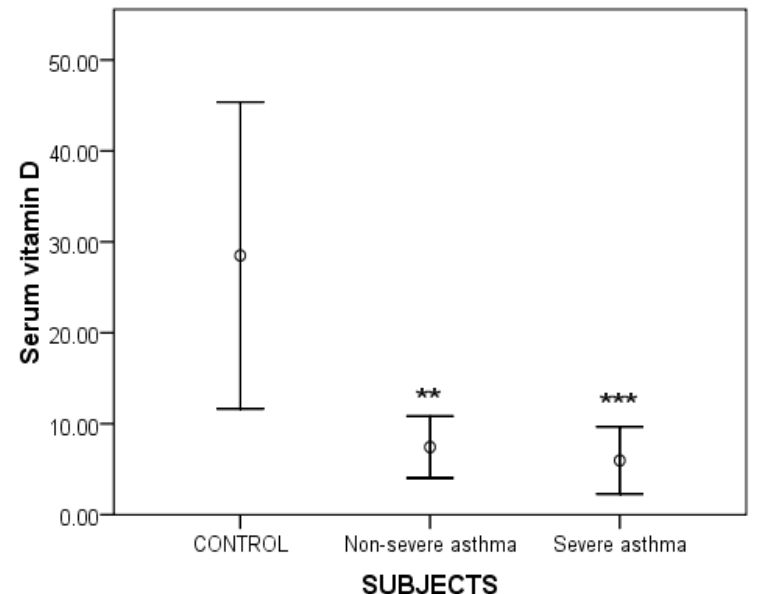

Error Bars: Mean+/- 1 SD

Figure 2: Comparison between serum vitamin D levels $(\mathrm{ng} / \mathrm{ml})$ in the three studied groups (control, non-severe and severe asthma)

**: Comparison between controls and non-severe asthma statistically significant at $\mathrm{p} \leq 0.01$

$* * *$ :Comparison between controls and severe asthma statistically significant at $\mathrm{p} \leq 0.001$

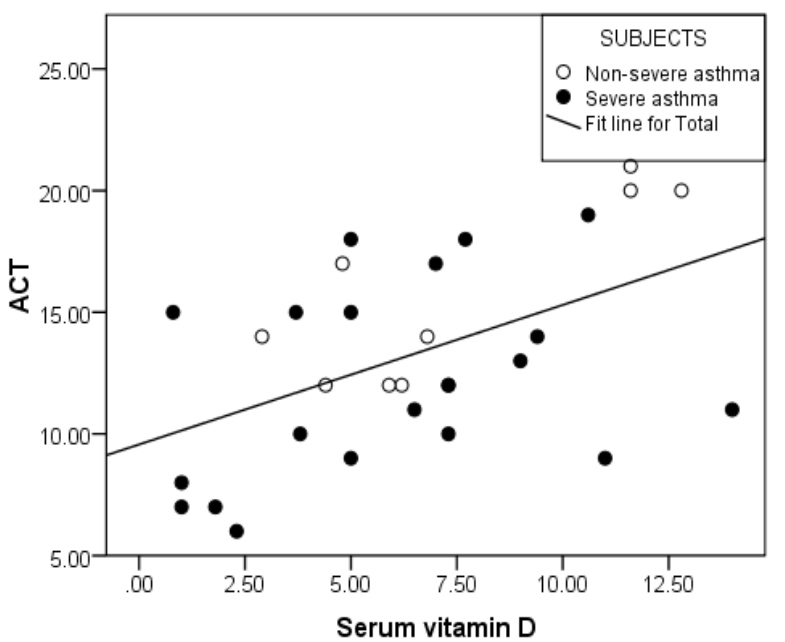

Figure 3: Correlation between serum vitamin $D$ levels (ng/ml) and ACT. $(r=0.498, p=0.005)$

ACT: Asthma Control Test, r: Pearson coefficient

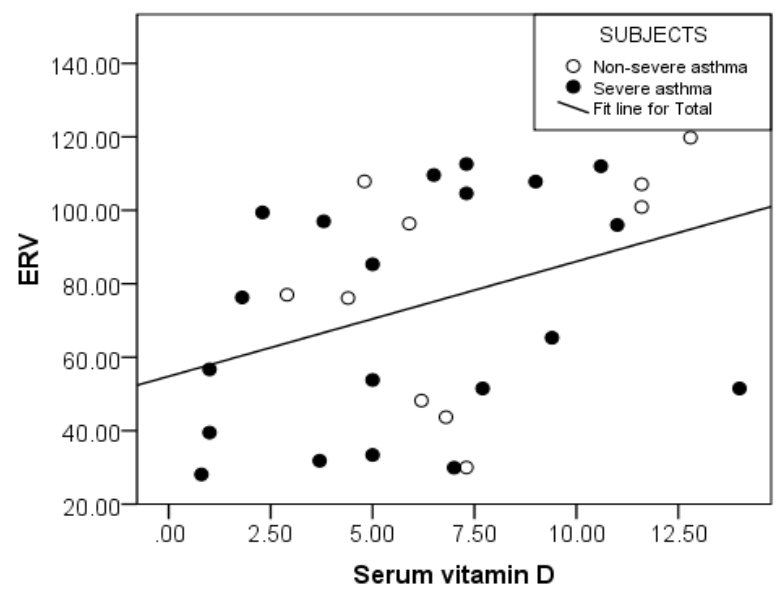

Figure 4: Correlation between serum vitamin D levels (ng/ml) and ERV in asthma patients $(\mathrm{r}=0.498, \mathrm{p}=0.005)$. ERV: Expiratory reserve volume, $r$ : Pearson coefficient

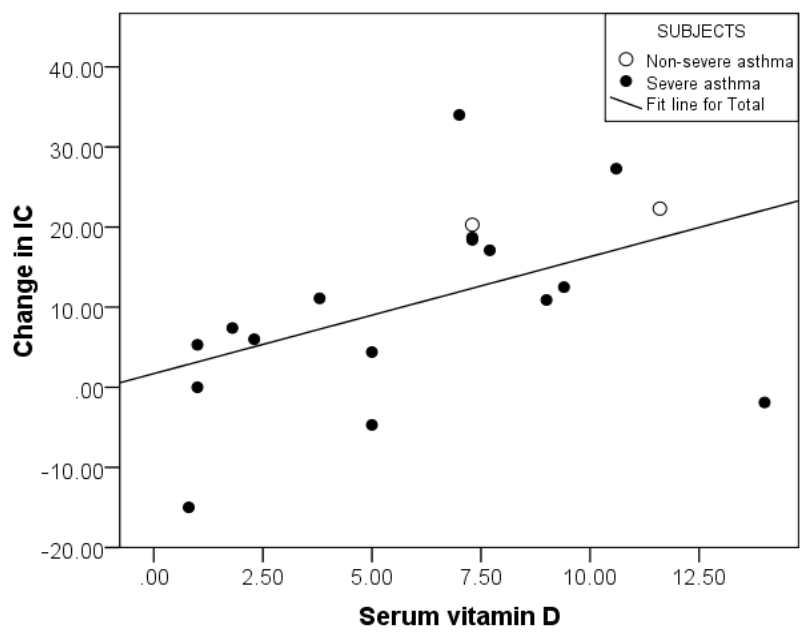

Figure 5: Serum vitamin D and bronchodilator responsiveness. Correlation between serum vitamin $\mathrm{D}(\mathrm{ng} / \mathrm{ml})$ and increases in IC ( $\mathrm{r}=0.473, \mathrm{p}=0.048)$

IC: Inspiratory capacity, $r$ : Pearson coefficient

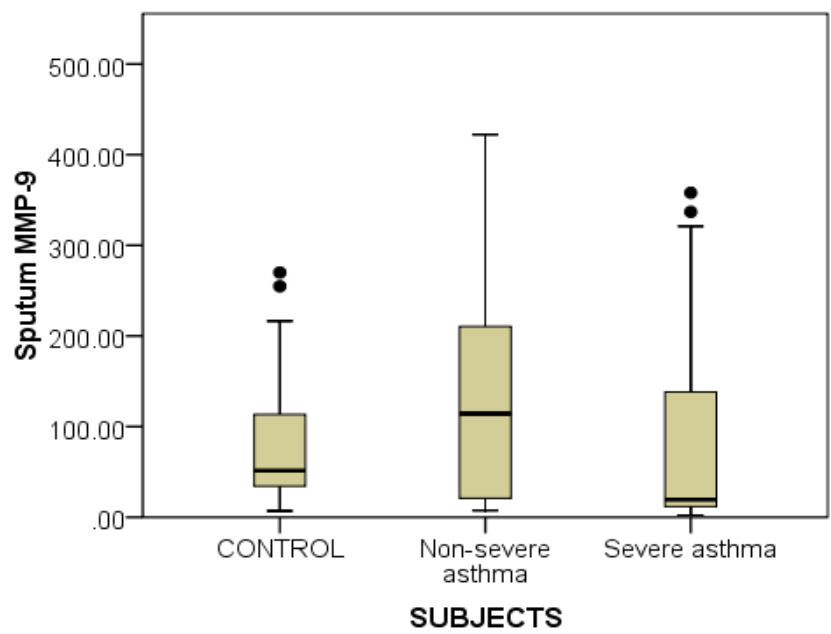

Figure 6: Comparison between sputum MMP-9 levels (ng/ml) (Median (Min-Max) in the three studied groups (control, non-severe and severe asthma patients).MMP-9: Matrix metalloproteinase-9.

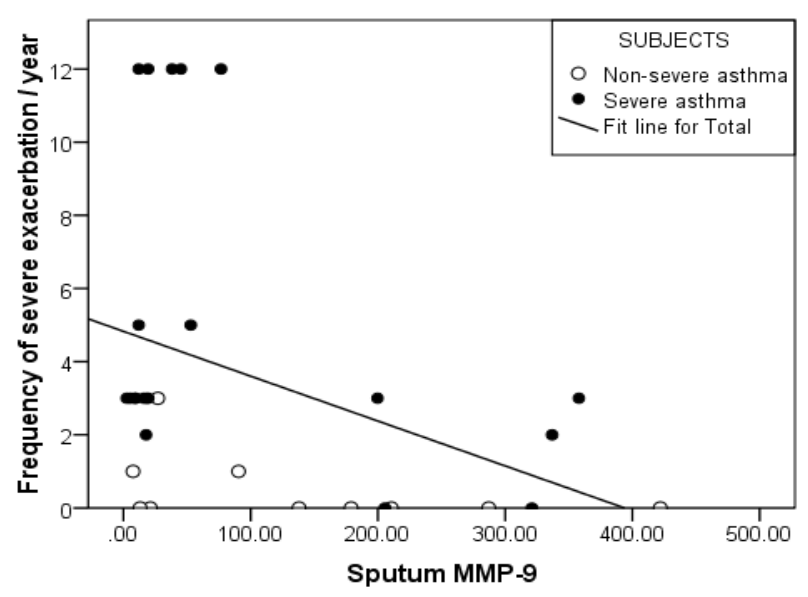

Figure 7: Correlation between sputum MMP-9 levels (ng/ml) and frequency of severe asthma exacerbation(s) in the previous year in asthma patients $\left(\mathrm{r}_{\mathrm{s}}=-0.396, \mathrm{p}=0.030\right)$. MMP-9: Matrix metalloproteinase- $9, \mathrm{r}_{\mathrm{s}}$ : Spearman coefficient, 


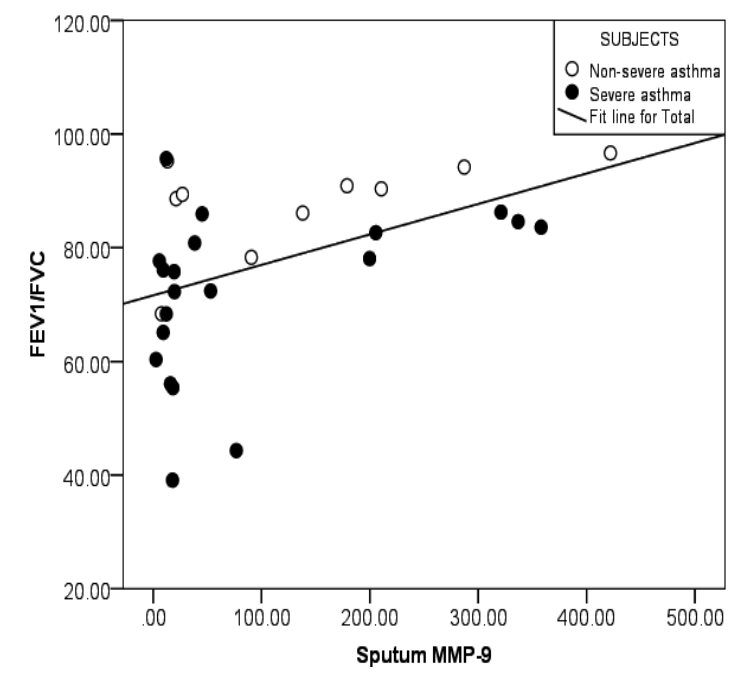

Figure 8:Correlations between sputum MMP-9 levels and $\mathrm{FEV}_{1} / \mathrm{FVC} \%$ $\left(r_{s}=0.504, p=0.005\right)$. in asthma patients MMP-9: Matrix metalloproteinase-9, $\mathrm{FEV}_{1}$ : forced expiratory volume in 1 second, FVC: forced vital capacity.

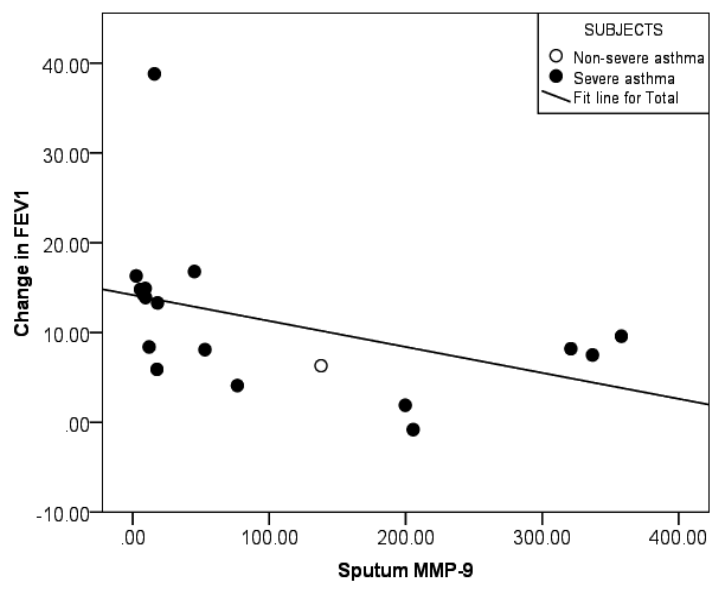

Figure 9: Correlations between sputum MMP-9 levels and change in $\mathrm{FEV}_{1}$ in asthma patients with airway obstruction $\left(\mathrm{r}_{\mathrm{s}}=-0.639\right.$, $\mathrm{p}=0.004)$.

MMP-9: Matrix metalloproteinase-9, $\mathrm{FEV}_{1}$ : forced expiratory volume in 1 second, $\mathrm{r}_{\mathrm{s}}$ : Spearman coefficient.

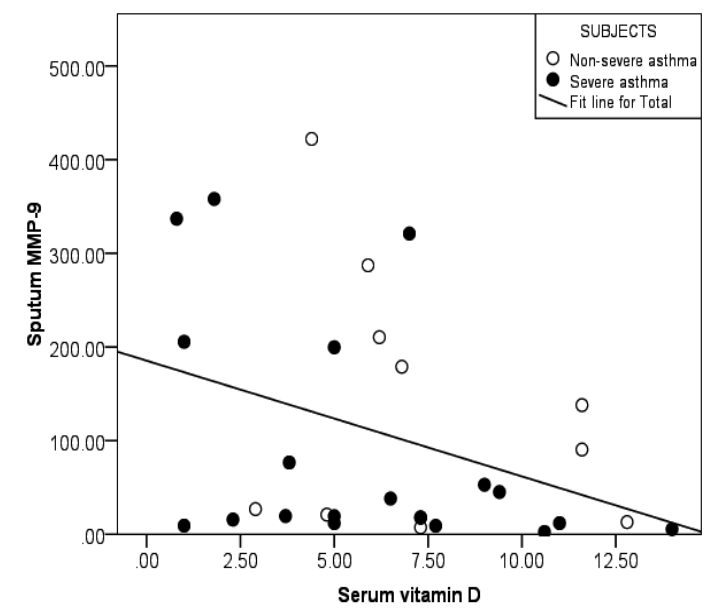

Figure 10: Correlation between serum vitamin $\mathrm{D}(\mathrm{ng} / \mathrm{ml})$ and sputum MMP-9 levels $(\mathrm{ng} / \mathrm{ml})$ in asthma patients $\left(\mathrm{r}_{\mathrm{s}}=-0.377, \mathrm{p}=0.040\right)$. MMP-9: Matrix metalloproteinase-9, $\mathrm{r}_{\mathrm{s}}$ : Spearman coefficient

\section{DISCUSSION}

All our asthma patients had vitamin D deficiency $(<20 \mathrm{ng} / \mathrm{ml})$, with no significant difference in serum vitamin D levels between non-severe and severe asthma. Meanwhile, only $33.3 \%$ of controls had vitamin D deficiency. Consistent with our results, some studies reported that most of asthma patients had vitamin D deficiency. ${ }^{(24,25)}$ Other studies reported a lower prevalence of vitamin D deficiency among asthma patients. ${ }^{(26,27)}$

The high prevalence of vitamin D deficiency among our asthma patients could be attributed to several factors including season and latitude, behavioural factors affecting sun exposure and dietary habits. ${ }^{(9)}$ In addition, genetic factors $^{(28)}$ and chronic corticosteroid administration. ${ }^{(29)}$ may contribute to vitamin D deficiency in asthma patients.

Our present study was carried out in winter (from November 2012 until February 2013) in Alexandria (latitude $\left.31^{\circ} \mathrm{N}\right)$. Brehm et al $(2010)^{(30)}$ and Korn et al $(2013)^{(26)}$ demonstrated that vitamin D level in asthma patients varied by season with highest levels in summer and lowest levels in winter and spring.

The high percentage of vitamin D deficiency in our asthma patients $(100 \%)$ was similar to that reported by $\mathrm{Li}$ et al $(2011)^{(25)}$ in asthmatic adults from China (89\%), who were at a near altitude to ours (latitude $39^{\circ} \mathrm{N}$ ). Studies carried out in equatorial populations, from Costa Rica (latitude, $10^{\circ} \mathrm{N}$ ) and Puerto Rico (latitude, $18^{\circ} \mathrm{N}$ ), demonstrated a lower percentage of vitamin D insufficiency among children with asthma, 28\% and $44 \%$ respectively. ${ }^{(31,}$ 32) However, Montero-Arias et al $(2013)^{(27)}$ reported a higher percentage of vitamin D insuffeciency (90\%) among adults asthma patients from Costa Rica.

Meanwhile, northern populations showed different results. Gupta et al (2011) ${ }^{(24)}$ reported a high percentage of vitamin D deficiency among children with asthma (94\% in severe and $54 \%$ in moderate asthma patients) in United Kingdom (London, latitude $51^{\circ} \mathrm{N}$ ). In a study carried out in Italy (latitude $45^{\circ} \mathrm{N}$ ) during the winter and early spring, Chinellato et al (2011) ${ }^{(33)}$ reported that about $53 \%$ of children with asthma had vitamin D deficiency. In Germany (latitude $\left.50^{\circ} \mathrm{N}\right)$, Korn et al $(2013){ }^{(26)}$ reported that about $33 \%$ of asthma patients were vitamin D deficient. Interestingly, the latter study reported seasonal variations in vitamin $\mathrm{D}$ level being highest in summer and lowest in winter and spring. On the other hand, in the United States (Denver, latitude $39^{\circ} \mathrm{N}$ ), Searing et al $(2010)^{(34)}$ reported that $17 \%$ of asthmatic children had vitamin D deficiency. However, most of the latter study was performed in the summer. ${ }^{(34)}$

In our study, we found a significant positive relationship between serum vitamin D levels and ACT. However, there was no significant correlation between serum vitamin D levels and frequency of asthma exacerbations in the previous year. Consistent with our results, Gupta et al (2011) ${ }^{(24)}$ and Chinellato et al (2011) ${ }^{(33)}$ found a significant positive association between serum vitamin D 
levels and childhood ACT. In addition, Chinellato et al (2011) (33) and Korn et al (2013) (26) assessed asthma control using GINA classification where higher serum vitamin D level was associated with higher level of asthma control. Several studies reported that lower serum vitamin D levels were associated with more frequent asthma exacerbations in children. ${ }^{(24,30-32)}$ However, in adults asthmatics, exacerbations were usually assessed as a part of asthma control as described by GINA guidelines. $^{(26)}$

Asthma Control Test (ACT) is used to evaluate asthma symptom control over the previous four weeks ${ }^{(14)}$, while exacerbations usually reflects the control over a longer duration(12months) ${ }^{(35)}$ Exacerbations should be considered separately from current clinical control when evaluating overall asthma control because exacerbations may occur even if the patient has adequate day-to-day control of symptoms and minimal activity limitations. ${ }^{(1,35)}$ Thus, our results suggest that, in adult asthma patients, serum vitamin $\mathrm{D}$ level is related to current clinical control rather than long-term asthma control.

As regards pulmonary function tests, serum vitamin D level was positively correlated with ERV. ERV could be linked to expiratory effort. ${ }^{(15)}$ All our patients were vitamin D deficient. Vitamin D deficiency has been associated with skeletal muscle weakness. ${ }^{(36)}$ Moreover, vitamin $\mathrm{D}$ and calcium supplementation have been associated with enhanced skeletal muscle strength including respiratory muscles. (37) Thus, the positive correlation between serum vitamin D and ERV could be attributed to vitamin D deficiency induced myopathy affecting respiratory muscles.

There was no significant association between serum vitamin D levels and $\mathrm{FEV}_{1}$ in our asthma patients. Several studies demonstrated a positive correlation between serum vitamin D levels and $\mathrm{FEV}_{1}$ in asthma patients. ${ }^{(24,25,38)}$ In an analysis in one of these studies (Sutherland et al $\left.(2010)^{(38)}\right)$, when asthmatic patients were stratified into inhaled corticosteroid (ICS) treated and ICS untreated, a stronger relationship between $\mathrm{FEV}_{1}$ and vitamin $\mathrm{D}$ was observed in those subjects with asthma not currently receiving ICS versus those who were. In addition, Montero-Arias et al (2013) (27) found no significant association between serum vitamin $\mathrm{D}$ levels and $\mathrm{FEV}_{1}$ in asthmatic patients, most of whom were on either high dose ICS or OCS. Thus, corticosteroid treatment could modify the relation between serum vitamin D levels and $\mathrm{FEV}_{1}$ in asthmatic patients.

After bronchodilatation, improvements in IC were positively correlated with serum vitamin D in our asthma patients with airway obstruction. Improvement in IC after salbutamol inhalation has been reported in patients with hyperinflation. ${ }^{(39)}$ This bronchodilator response is due to ASM relaxation, which could be related to ASM mass ${ }^{(4)}$. Similarly, Gupta et al (2011) (24) demonstrated a significant positive association between serum vitamin $D$ and the degree of bronchodilator reversibility in children with severe therapy-resistant asthma (STRA). Bronchial biopsies from children with STRA showed a significant negative association between serum vitamin D levels and volume fraction of ASM. ${ }^{(24)}$

Increased ASM mass has been associated with persistent airway obstruction in patients with severe asthma. ${ }^{(4)}$ It is therefore plausible that the link between reduced bronchodilator responsiveness in severe asthma and increased ASM, an important feature of airway remodelling in severe asthma, may partly be explained by low serum vitamin $\mathrm{D}$ levels.

The association between increased ASM mass and low vitamin D levels is supported by in vitro studies, which have shown that vitamin D inhibits ASM proliferation $^{(11,12,40)}$. Vitamin D blocked smooth muscle proliferation in a concentration-dependent manner in human ASM cells sensitized with asthmatic serum. ${ }^{(11)}$ However, we acknowledge that these ideas remain speculative at the present time and the determination of the exact mechanism between low vitamin $\mathrm{D}$ and airway remodelling in severe asthma will require intervention studies.

MMP-9 is one of the major proteinases that are involved in airway remodelling in asthma, $\left.{ }^{5}, 41\right)$ as it has been associated with increased deposition of ECM proteins ${ }^{(6)}$, ASM mass ${ }^{(7)}$ and airway wall thickness detected by high resolution computerized tomography (HRCT), ${ }^{(42)}$ in patients with asthma. We found no significant differences in sputum MMP-9 levels between the three studied groups (controls, non-severe and severe asthmatics). However, sputum MMP-9 levels were negatively correlated with the frequency of severe exacerbations (i.e. requiring systemic $\mathrm{CS}$ ) in the previous year. Thus, the use of systemic corticosteroids could have decreased sputum MMP-9 levels.

Several studies described the effect of systemic corticosteroid treatment on MMP-9 levels in asthmatic patients. Consistent with our results, Tanaka et al (2000) ${ }^{(43)}$ and Lee et al (2001) ${ }^{(44)}$ demonstrated that sputum MMP-9 levels were significantly decreased after systemic corticosteroid treatment. MMP-9 is expressed by various inflammatory and structural cells that are decreased by corticosteroid treatment. ${ }^{(41,45)}$ In vitro human studies also demonstrated that corticosteroids down-regulated the production of MMP-9 from alveolar macrophage (46) and lung fibroblasts. (47) This could explain the negative association between sputum MMP-9 and the use of systemic CS in our study.

In our study, although sputum MMP-9 was positively correlated with $\mathrm{FEV}_{1} / \mathrm{FVC}$ and PEF, it was negatively associated with the degree of increase in $\mathrm{FEV}_{1}$. Wang et al (2011) ${ }^{(42)}$ demonstrated that sputum MMP-9 levels were positively correlated with airway wall thickness, as detected by HRCT. However, airway wall thickness was correlated negatively with $\mathrm{FEV} / \mathrm{FVC} \%$ and $\mathrm{FEV}_{1 .}{ }^{(42)}$ In addition, Araujo et al (2008) ${ }^{(41)}$ demonstrated that MMP9 expression within the ASM cells is increased in large airways, in patients with fatal asthma when compared with non-asthma controls. This may explain the reduced bronchodilator reversibility associated with MMP-9 in our asthmatic patients. 
Thus, although MMP-9 was associated with reduced bronchodilator reversibility (the degree of increase in $\mathrm{FEV}_{1}$ ), it was associated with reduced degree of airway obstruction (positive correlation with $\mathrm{FEV}_{1} / \mathrm{FVC}$ ). This is consistent with a hypothesis stating that airway remodelling, and thereby stiffening of the airways occurring in asthmatic patients may protect them from excessive airway narrowing. ${ }^{(48)}$

In severe asthma, air trapping is believed to be due to premature airway closure resulting in reduced FVC. ${ }^{(49)} \mathrm{A}$ force that opposes small airway narrowing and closure is airway-parenchymal coupling, which is a bronchodilating force obtained from the tethering effect of lung elastic recoil transmitted to the airway adventitial walls. Lung parenchymal mechanics are dominated by the ECM components, ${ }^{(50)}$ so a potential mechanism of reduced lung elastic recoil could be an alteration of matrix proteins. In addition, loss of alveolar-airway attachments ${ }^{(51)}$ may play a role. This may lead to reduction of airwayparenchymal coupling with subsequent air trapping in asthma. ${ }^{(51,52)}$

After bronchodilatation, sputum MMP-9 was negatively associated with FVC. MMP-9 expression is increased at the outer region of the small airways (located between the external ASM border and the external limits of the airway (alveolar parenchyma)) and in the peribronchiolar parenchyma in patients with fatal asthma when compared with non-asthma controls. (53) Thus, MMP-9 might contribute to functional changes and the loss of airwayparenchyma interdependence observed in asthmatic patients with resultant air trapping and reduced FVC ${ }^{(51,52)}$ In our study, serum vitamin D levels were negatively correlated with sputum MMP-9 levels in asthma patients. In an in vitro study, Song et al (2007) ${ }^{(11)}$ found that ASM cells passively sensitized with asthmatic serum have higher levels of MMP-9 as compared to non-asthmatic ASM cells. In vitro treatment with $1,25(\mathrm{OH})_{2} \mathrm{D}_{3}$ in asthmatic ASM cells reduced the mRNA and protein expression of MMP-9 to a level comparable to the nonasthmatic ASM cells. Thus, our results could be considered a clinical extrapolation of such a study suggesting a possible beneficial role for vitamin $D$ in preventing and treating asthmatic airway remodelling

In summary, we reported a high prevalence of vitamin D deficiency among our asthma patients. Although there was no significant difference in serum vitamin D levels between severe and non-severe asthmatic patients, serum vitamin D levels were positively correlated with the degree of current clinical control, as measured by ACT. In our asthma patients, serum vitamin D levels were negatively correlated with sputum MMP-9 levels, a mediator that has been implicated in airway remodelling. The degree of bronchodilator reversibility was correlated positively with serum vitamin $\mathrm{D}$ and negatively with sputum MMP-9 levels.

In conclusion, vitamin D deficiency was prevalent among our asthmatic patients. There was a positive association between serum vitamin $\mathrm{D}$ level and both asthma control and bronchodilator responsiveness. In addition, there was an inverse correlation between serum vitamin $\mathrm{D}$ and sputum MMP-9 levels. This suggests that vitamin D deficiency could play a role in the pathophysiology of airway remodelling in asthma. Accordingly, we suggest that vitamin $\mathrm{D}$ may have a beneficial role in the prevention of airway remodelling in asthmatic patients.

\section{REFERENCES}

1. Global Strategy for Asthma Management and Prevention. Global Initiative for Asthma (GINA), 2014. Available from www.ginasthma.org Date last updated, 2014.

2. Chipps BE, Zeiger RS, Borish L, et al. Key findings and clinical implications from The Epidemiology and Natural History of Asthma: Outcomes and Treatment Regimens (TENOR) study. J Allergy Clin Immunol 2012, 130(2): 332-42 e10.

3. Chung KF, Wenzel SE, Brozek JL, et al. International ERS/ATS guidelines on definition, evaluation and treatment of severe asthma. Eur Respir J 2014, 43(2): 343-73.

4. Kaminska M, Foley S, Maghni K, et al. Airway remodeling in subjects with severe asthma with or without chronic persistent airflow obstruction. J Allergy Clin Immunol 2009, 124(1):45-51 e1-4.

5. Vandenbroucke RE, Dejonckheere E, Libert C. A therapeutic role for matrix metalloproteinase inhibitors in lung diseases? Eur Respir J 2011, 38(5):1200-14.

6. Hoshino M, Nakamura Y, Sim J, et al. Bronchial subepithelial fibrosis and expression of matrix metalloproteinase-9 in asthmatic airway inflammation. J Allergy Clin Immunol 1998, 102(5):783-8.

7. Johnson C, Galis ZS. Matrix Metalloproteinase-2 and -9 Differentially Regulate Smooth Muscle Cell Migration and Cell-Mediated Collagen Organization. Arterioscler Thromb Vasc Biol 2004, 24(1):54-60.

8. Bradley LM, Douglass MF, Chatterjee D, et al. Matrix metalloprotease 9 mediates neutrophil migration into the airways in response to influenza virus-induced toll-like receptor signaling. PLoS Pathog 2012, 8(4):e1002641.

9. Hossein-nezhad A, Holick MF. Vitamin D for health: a global perspective. Mayo Clin Proc 2013, 88(7):720-55.

10. Paul G, Brehm JM, Alcorn JF, et al. Vitamin D and Asthma. Am J Respir Crit Care Med 2012, 185(2):124-32.

11. Song Y, Qi H, Wu C. Effect of 1,25-(OH)2D3 (a vitamin $\mathrm{D}$ analogue) on passively sensitized human airway smooth muscle cells. Respirology 2007, 12(4): 486-94.

12. Damera G, Fogle HW, Lim P, et al. Vitamin D inhibits growth of human airway smooth muscle cells through growth factor-induced phosphorylation of retinoblastoma protein and checkpoint kinase 1. Br J Pharmacol 2009, 158(6):1429-41.

13. Proceedings of the ATS Workshop on Refractory Asthma: Current Understanding, Recommendations, and Unanswered Questions. Am J Respir Crit Care Med 2000, 162(6):2341-51.

14. Nathan RA, Sorkness CA, Kosinski M, et al. Development of the asthma control test: a survey for assessing asthma control. J Allergy Clin Immunol 2004, 113(1):59-65.

15. Miller MR, Hankinson J, Brusasco V, et al. Standardisation of spirometry. Eur Respir J 2005, 26(2): 319-38.

16. Pellegrino R, Viegi G, Brusasco V, et al. Interpretative strategies for lung function tests. Eur Respir J 2005, 26 (5): 948-68.

17. Turpeinen U, Hohenthal U, Stenman UH. Determination of 25-hydroxyvitamin $\mathrm{D}$ in serum by HPLC and immunoassay. Clin Chem 2003, 49(9):1521-4. 
18. Holick MF, Binkley NC, Bischoff-Ferrari HA, et al. Evaluation, treatment, and prevention of vitamin D deficiency: an Endocrine Society clinical practice guideline. J Clin Endocrinol Metab 2011, 96(7):1911-30.

19. Ross AC, Manson JE, Abrams SA, et al. The 2011 report on dietary reference intakes for calcium and vitamin D from the Institute of Medicine: what clinicians need to know. J Clin Endocrinol Metab 2011, 96 (1):53-8.

20. Paggiaro PL, Chanez P, Holz O, et al. Sputum induction. Eur Respir J 2002, 20 (Suppl 37):3s-8s.

21. Pizzichini E, Pizzichini MMM, Leigh R, et al. Safety of sputum induction. Eur Respir J 2002, 20 (Suppl.37):9s-18s.

22. Efthimiadis A, Spanevello A, Hamid Q, et al. Methods of sputum processing for cell counts, immunocytochemistry and in situ hybridisation. Eur Respir J 2002, 20 (Suppl. 37):19s-23s.

23. Kelly MM, Keatings V, Leigh R,et al. Analysis of fluidphase mediators. Eur Respir J 2002, 20(Suppl. 37):24s-39s.

24. Gupta A, Sjoukes A, Richards D, et al. Relationship between serum vitamin $\mathrm{D}$, disease severity, and airway remodeling in children with asthma. Am J Respir Crit Care Med 2011, 184(12):1342-9.

25. Li F, Peng M, Jiang L, et al. Vitamin D deficiency is associated with decreased lung function in Chinese adults with asthma. Respiration 2011, 81(6):469-75.

26. Korn S, Hubner $\mathrm{M}$, Jung $\mathrm{M}$, et al. Severe and uncontrolled adult asthma is associated with vitamin D insufficiency and deficiency. Respir Res 2013, 14(1):25.

27. Montero-Arias F, Sedó-Mejía G, Ramos-Esquivel A. Vitamin D Insufficiency and Asthma Severity in Adults From Costa Rica. Allergy Asthma Immunol Res 2013, 5(5):283-8.

28. Bosse Y, Lemire M, Poon AH, et al. Asthma and genes encoding components of the vitamin D pathway. Respir Res 2009, 10:98.

29. Davidson ZE, Walker KZ, Truby H. Do Glucocorticosteroids Alter Vitamin D Status? A Systematic Review with Meta-Analyses of Observational Studies. J Clin Endocrinol Metab 2012, 97(3):738-44.

30. Brehm JM, Schuemann B, Fuhlbrigge AL, et al. Serum vitamin D levels and severe asthma exacerbations in the Childhood Asthma Management Program study. J Allergy Clin Immunol 2010, 126(1):52-8.e5.

31. Brehm JM, Celedón JC, Soto-Quiros ME, et al. Serum Vitamin D Levels and Markers of Severity of Childhood Asthma in Costa Rica. Am J Respir Crit Care Med 2009, 179(9):765-71.

32. Brehm JM, Acosta-Pérez E, Klei L, et al. Vitamin D Insufficiency and Severe Asthma Exacerbations in Puerto Rican Children. Am J Respir Crit Care Med 2012, 186 (2):140-6.

33. Chinellato I, Piazza M, Sandri M, et al. Vitamin D serum levels and markers of asthma control in Italian children. J Pediatr 2011, 158(3):437-41.

34. Searing DA, Zhang Y, Murphy JR, et al. Decreased serum vitamin D levels in children with asthma are associated with increased corticosteroid use. J Allergy Clin Immunol 2010, 125(5):995-1000.

35. Bousquet J, Mantzouranis E, Cruz AA, et al. Uniform definition of asthma severity, control, and exacerbations: document presented for the World Health Organization Consultation on Severe Asthma. J Allergy Clin Immunol 2010, 126(5):926-38.
36. Girgis CM, Clifton-Bligh RJ, Hamrick MW, et al. The Roles of Vitamin D in Skeletal Muscle: Form, Function, and Metabolism. Endocrine Reviews 2013, 34(1):33-83.

37. Gupta R, Sharma U, Gupta N, et al. Effect of cholecalciferol and calcium supplementation on muscle strength and energy metabolism in vitamin D-deficient Asian Indians: a randomized, controlled trial. Clin Endocrinol (Oxf) 2010, 73(4):445-51.

38. Sutherland ER, Goleva E, Jackson LP, et al. Vitamin D levels, lung function, and steroid response in adult asthma. Am J Respir Crit Care Med 2010, 181(7):699-704.

39. Newton MF, O'Donnell DE, Forkert L. Response of lung volumes to inhaled salbutamol in a large population of patients with severe hyperinflation. Chest 2002, 121(4): 1042-50.

40. Banerjee A, Damera G, Bhandare R, et al. Vitamin D and glucocorticoids differentially modulate chemokine expression in human airway smooth muscle cells. $\mathrm{Br} \mathrm{J}$ Pharmacol 2008, 155(1):84-92.

41. Araujo BB, Dolhnikoff M, Silva LF, et al. Extracellular matrix components and regulators in the airway smooth muscle in asthma. Eur Respir J 2008, 32(1):61-9.

42. Wang K, Liu C-t, Wu Y-h, et al. Effects of formoterolbudesonide on airway remodeling in patients with moderate asthma. Acta Pharmacol Sin 2011, 32(1):126-32.

43. Tanaka H, Miyazaki N, Oashi K, et al. Sputum matrix metalloproteinase-9: Tissue inhibitor of metallo-proteinase1 ratio in acute asthma. J Allergy Clin Immunol 2000, 105 (5): 900-5.

44. Lee YC, Lee HB, Rhee YK, et al. The involvement of matrix metalloproteinase-9 in airway inflammation of patients with acute asthma. Clin Exp Allergy 2001, 31(10): 1623-30.

45. Kelly MM, O'Connor TM, Leigh R, et al. Effects of budesonide and formoterol on allergen-induced airway responses, inflammation, and airway remodeling in asthma. J Allergy Clin Immunol 2010, 125(2):349-56 e13.

46. Mautino G, Oliver N, Chanez P, et al. Increased release of matrix metalloproteinase- 9 in bronchoalveolar lavage fluid and by alveolar macrophages of asthmatics. Am J Respir Cell Mol Biol 1997, 17(5):583-91.

47. Todorova L, Gurcan E, Westergren-Thorsson G, et al. Budesonide/ formoterol effects on metalloproteolytic balance in TGF $\beta$-activated human lung fibroblasts. Respir Med 2009, 103(11):1755-63.

48. McParland BE, Macklem PT, Pare PD. Airway wall remodeling: friend or foe? J Appl Physiol 2003, 95(1): 426-34.

49. in 't Veen JC, Beekman AJ, Bel EH, et al. Recurrent exacerbations in severe asthma are associated with enhanced airway closure during stable episodes. Am J Respir Crit Care Med 2000, 161(6):1902-6.

50. Faffe DS, Zin WA. Lung Parenchymal Mechanics in Health and Disease. Physiol Rev 2009, 89(3):759-75.

51. Mauad T, Silva LF, Santos MA, et al. Abnormal alveolar attachments with decreased elastic fiber content in distal lung in fatal asthma. Am J Respir Crit Care Med 2004, 170(8):857-62.

52. Gelb AF, Licuanan J, Shinar CM, et al. Unsuspected loss of lung elastic recoil in chronic persistent asthma. Chest 2002, 121(3):715-21.

53. Dolhnikoff M, da Silva LF, de Araujo BB, et al. The outer wall of small airways is a major site of remodeling in fatal asthma. J Allergy Clin Immunol 2009, 123(5): 1090-7, 7 e1 